J. Lake Sci. (湖泊科学), 2007, 19(4): 421-427

http://www. jlakes. org. E-mail: jlakes@ niglas. ac.cn

(c) 2007 by Journal of Lake Sciences

\title{
鄱阳湖流域乐安河重金属污染水平
}

\author{
万金保,间伟伟**，谢 婷
}

（南昌大学环境科学与工程学院教育部鄱阳湖湖泊生态与生物资源利用实验室,南昌,330029)

摘 要: 乐安河是鄱阳湖五大人湖水系中重金属污染最严重的水域. 为研究其污染现状, 于 $2003-2004$ 年度对乐安河水 体、底泥及水生生物的重金属污染进行了调查与分析. 结果表明,乐安河水体中的重金属除 $\mathrm{Cu}$ 的含量超出地表水环境质 量标准 III 类标准外,其它各项监测指标均能达到地表水环境质量 III 类标准. 乐安河底泥的重金属含量平均值与国家土壤 环境质量相比, $\mathrm{Cu}$ 的平均值超出了三级标准, 而 $\mathrm{Pb}$ 和 $\mathrm{Zn}$ 的含量指标均符合三级标准; 通过地质累积指数评价结果表明, 乐安河底泥中 $\mathrm{Cu}$ 为严重污染, $\mathrm{Pb}$ 为偏中度污染, $\mathrm{Zn}$ 为中度污染. 乐安河水生植物对 $\mathrm{Cu}, \mathrm{Pb}, \mathrm{Zn}$ 都有不同程度的富集, 根 据富集系数评价表明, 植物对 $\mathrm{Cu}$ 的平均富集能力相对较强, 其次是 $\mathrm{Pb}$ 和 $\mathrm{Zn}$. 浮游动物、植物和底栖动物也受到不同程度 的污染,其分布和数量因河段水质变化的影响也出现类似的波动.

关键词: 乐安河;底泥;水生生物;重金属污染; 鄱阳湖流域

\section{Research on heavy metals pollution status of Le' an River, Lake Poyang Basin}

WAN Jinbao, YAN Weiwei \& XIE Ting

(Key Lab. of Lake Poyang Ecology and Bio-resource Utilization, Environment Science and Technology College, Nanchang University, Nanchang 330029, P. R. China)

\begin{abstract}
The Le' an River is the most seriously heavy metals polluted area of five rivers into Lake Poyang. Based on a survey of heavy metal pollution status of water, sediment and aquatic organisms during $2003-2004$, the results indicate that the content of every component except $\mathrm{Cu}$ in the water meet class III criterion for surface water evaluation. Comparing with environmental quality standard for soils, the average sediment concentration of $\mathrm{Pb}$ and $\mathrm{Zn}$ in sediment did meet class III criterion except $\mathrm{Cu}$. The indexes of geography accumulation results indicate that $\mathrm{Cu}$ pollution has nearly reached a serious stage of pollution, and $\mathrm{Pb}$ and $\mathrm{Zn}$ only superficially pollute the sediment. $\mathrm{Cu}, \mathrm{Pb}$ and $\mathrm{Zn}$ are enriched differently by aquatic plants in the sampling sites. According to the assessment of enrichment coefficient, the average enrichment coefficient of $\mathrm{Cu}$ pollution in aquatic plants was relatively higher than $\mathrm{Pb}$ and $\mathrm{Zn}$. Zooplankton, phytoplankton and benthos species had been polluted at different extents, the distribution and amount of which had similarly fluctuated according to the variation of water quality.
\end{abstract}

Keywords: Le' an River; sediment; aquatic organisms; heavy metals pollution; Lake Poyang Basin

乐安河源于江西省与浙江省的交界处,流经敬源、德兴、乐平、波阳等县市,在龙口处进人鄱阳湖,全长 $279 \mathrm{~km}^{[1]}$. 自上个世纪 50 年代以来, 沿河陆续办起了三个大矿山, 其中有亚洲最大的铜矿一德兴铜矿, 还有 一个造纸厂,几家制药厂、化工厂和有色金属冶炼厂等,加上沿河生活污水等非点源的污染,致使该河流的 诸多污染指标严重超标,其中酸性废水和重金属污染尤其严重,特别是重金属元素 $\mathrm{Cu} 、 \mathrm{~Pb} 、 \mathrm{Zn}$ 等的污染使 德兴铜矿下游的几个村的几百公顷良田变成了荒地, 甚至波及到鄱阳湖的底泥 ${ }^{[2,3]}$, 从而对人、畜、鸟类等 生命健康造成了潜在的危害,调查研究乐安河的重金属污染水平具有十分重要的意义.

* 江西省科学技术厅科技攻关项目 (2004B0304300) 资助. 2006-06-06 收稿;2006-12-1 收修改稿. 万金保,男, 1952 年生,教授,博士生导师;E-mail: jbwan@ ncu. edu. cn.

** 通讯作者; E-mail:yanww_219@163.com. 


\section{1 材料和方法}

\section{1 采样点设置}

本文研究的样品是 $2003-2004$ 年度平水期采自鄱阳湖乐安河段——乐安河源头处海口至人鄱阳湖处 龙口整个流域, 共布设 12 个监测点, 同时以未受污染的源头海口处作为对照点 (图 1). 样品主要为各采样 点的水样、底泥、水生动植物等, 监测指标主要有各样品中的 $\mathrm{Cu} 、 \mathrm{~Pb} 、 \mathrm{Zn}$ 等, 辅助调查项目有水样 $\mathrm{pH}$ 值, 底 泥的 $\mathrm{pH}$ 值、有机质, 水生植物的盖度和多度等.

\section{2 样品处理}

1.2 .1 水样处理 现场采取水样, 测定 $\mathrm{pH}$ 值, 过滤后加人硝酸固定, 以带回实验室处理. 各水样项目均按照 国家标准分析方法或者国家环保局组织编写的《水和废水监测分析方法》所规定的分析方法进行检测 ${ }^{[4]}$.

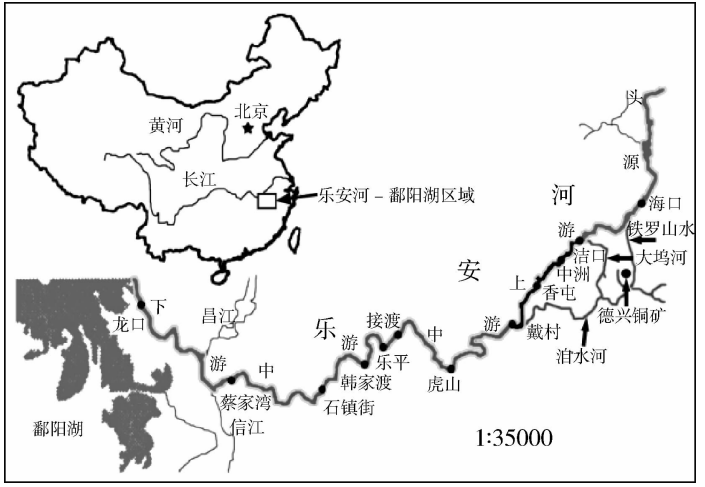

图 1 乐安河采样点布设图

Fig. 1 Sampling sites in the Le' an River

1.2 .2 底泥样品处理 现场采取底泥样品,用封口 的聚乙烯塑料袋装好带回实验室. 采用全分解方 法 $^{[5]}$, 称取 $0.1000 \mathrm{~g}$ 样品, $85^{\circ} \mathrm{C}$ 干燥 $24 \mathrm{~h}$, 粉碎, 加人 $2 \mathrm{ml}$ 浓 $\mathrm{HCl} 、 6 \mathrm{ml}$ 浓 $\mathrm{HNO}_{3} 、 1 \mathrm{ml}$ 浓 $\mathrm{HClO}_{4}$ 消化, 定 容、过滤. 水样测量 $\mathrm{pH}$ 值后, 摇匀, 取 $5 \mathrm{ml}$ 放人凯式 瓶中, 置烘箱内 $80^{\circ} \mathrm{C} 、 24 \mathrm{~h}$ 将水分蒸干, 向残余物加 $2 \mathrm{ml}$ 浓 $\mathrm{HCl} 、 1 \mathrm{ml}$ 浓 $\mathrm{HNO}_{3} 、 0.5 \mathrm{ml}$ 浓 $\mathrm{HClO}_{4}$ 消化, 定 容、过滤, 按上述水样重金属的标准方法测定.

1.2 .3 水生生物样品处理 对于水生植物, 采取优 势种群采样方法, 即在采样点附近采集常见水草. 将 采集到的样品带回实验室, 用自来水冲洗干净, 再用 超纯水漂洗, 放人 $105^{\circ} \mathrm{C}$ 电热干燥箱烘干 $5 \mathrm{~h}$. 干样粉 碎, 消解, 定容、过滤, 按水样重金属的标准方法测 定,同时做试剂空白试验.

对于水生浮游生物, 分别用 13 号 (浮游动物网) 和 25 号 (浮游植物网) 篮娟网在水表层采集. 定量样品 则在水中层取样. 每次 $1 \mathrm{~L}$, 用 $40 \%$ 福尔马林液固定,沉淀浓缩到 $30 \mathrm{ml}$, 常规方法定量计数.

\section{3 仪器、试剂与测定方法}

水样和底泥 $\mathrm{pH}$ 值的测定采用 HI92240 型便携式测 $\mathrm{pH}$ 测定仪 $( \pm 0.01 \mathrm{pH})$; 重金属元素含量采用 3510 型原子吸收分光光度计测定, 水样中 $\mathrm{Cu} 、 \mathrm{~Pb} 、 \mathrm{Zn}$ 等重金属元素总量的测定采用国家标准方法 ${ }^{[6]}$ 进行测定, 水样中重金属的含量均以 $\mathrm{mg} / \mathrm{L}$ 计, 测定下限为 $0.001 \mathrm{mg} / \mathrm{L}$; 底泥及植物中的重金属测定采用国家标准方 法 $^{[5]}$, 有机质运用重铬酸钾容量法测定; 底泥及植物样品中的重金属含量均为样品的干基含量 (以 $\mathrm{mg} / \mathrm{kg}$ 计, 测定下限为 $0.001 \mathrm{mg} / \mathrm{kg}$ ).

药品浓硝酸、高氯酸均为优级纯, 浓盐酸为分析纯.

\section{2 结果与讨论}

\section{1 乐安河水体重金属污染状况}

对采样点水样进行性状分析, 水样外观稍呈浑浊, 现场测定 $\mathrm{pH}$ 值, 水样经过滤、硝酸固定后带回实验 室消解处理并过滤后进行重金属含量测定,测定结果及相关地表水标准如表 1 所示.

表 1 结果显示,各样点水体中的重金属含量相对都较低,除沽口处 $\mathrm{Cu}$ 的含量超出地表水环境质量标准 III 类标准外, 其它各项监测指标及 $\mathrm{pH}$ 值均能达到地表水环境质量 II 类标准, 且多数样点中检出 $\mathrm{Pb} 、 \mathrm{Zn}$ 的 含量甚至达到了地表水环境质量 I 类标准. 由于乐安河上游德兴铜矿等大型非点源污染企业 ${ }^{[7]}$, 且水体直 接由乐安河经由龙口汇人鄱阳湖, 在一定程度上造成鄱阳湖重金属污染的直接隐患, 因此, 对乐安河水体中 的重金属污染应引起足够的重视. 
表 1 不同采样点水样 $\mathrm{pH}$ 值及重金属元素含量 $(\mathrm{mg} / \mathrm{L})$

Tab. $1 \mathrm{pH}$ and Contents of heavy metals in water of different sampling sites

\begin{tabular}{cccccc}
\hline 编号 & 名称 & $\mathrm{pH}$ & $\mathrm{Cu}$ & $\mathrm{Pb}$ & $\mathrm{Zn}$ \\
\hline $\mathrm{W}-1$ & 海口 & 7.52 & 未检出 & 未检出 & 0.003 \\
$\mathrm{~W}-2$ & 沽口 & 4.81 & 3.905 & 0.021 & 0.053 \\
$\mathrm{~W}-3$ & 中洲 & 7.06 & 0.518 & 0.006 & 0.027 \\
$\mathrm{~W}-4$ & 香屯 & 6.18 & 0.504 & 0.004 & 0.019 \\
$\mathrm{~W}-5$ & 戴村 & 6.28 & 0.388 & 0.005 & 0.059 \\
$\mathrm{~W}-6$ & 虎山 & 6.86 & 0.028 & 0.006 & 0.047 \\
$\mathrm{~W}-7$ & 接渡 & 6.71 & 0.031 & 0.019 & 0.029 \\
$\mathrm{~W}-8$ & 镇桥 & 6.78 & 0.028 & 0.005 & 0.016 \\
$\mathrm{~W}-9$ & 韩家渡 & 6.86 & 0.014 & 0.005 & 0.016 \\
$\mathrm{~W}-10$ & 石镇街 & 6.88 & 0.011 & 0.005 & 0.010 \\
$\mathrm{~W}-11$ & 蔡家湾 & 6.95 & 0.057 & 未检出 & 0.010 \\
$\mathrm{~W}-12$ & 双港 & 7.15 & 0.01 & 未检出 & 未检出 \\
$\mathrm{W}-13$ & 龙口 & 7.27 & 0.009 & 未检出 & 未检出 \\
\hline 地表水环境质量标准 & $6-9$ & 1.0 & 0.05 & 1.0 \\
$(\mathrm{~GB} 3838-2002$, III 类 & & & & \\
\hline
\end{tabular}

\section{2 底泥重金属污染的特征}

2.2 .1 乐安河底泥重金属污染情况重金属在迁移转化的过程中,往往会由于沉积作用而富集到河流底泥 当中,而 $\mathrm{pH}$ 和有机质又是影响重金属沉积的一个重要因素 ${ }^{[8]}$, 故课题同样采集了乐安河底泥,并对其进行 了有机质和重金属含量测定 (表 2).

表 2 不同采样点底泥 $\mathrm{pH}$ 值、有机质及重金属元素含量 $(\mathrm{mg} / \mathrm{kg})$

Tab. 2 Contents of $\mathrm{pH}$, organic matter and heavy metals in sediment of different sampling sites

\begin{tabular}{|c|c|c|c|c|c|c|}
\hline 编号 & 名称 & $\mathrm{pH}$ & 有机质 & $\mathrm{Cu}$ & $\mathrm{Pb}$ & $\mathrm{Zn}$ \\
\hline$S-1$ & 海口 & 7.38 & 4.14 & 36 & 44 & 216 \\
\hline$S-2$ & 沽口 & 4.94 & 3.72 & 2878 & 42 & 221 \\
\hline$S-3$ & 中洲 & 5.46 & 2.62 & 2173 & 44 & 201 \\
\hline$S-4$ & 香屯 & 5.58 & 3.00 & 1788 & 69 & 202 \\
\hline$S-5$ & 戴村 & 6.24 & 3.02 & 1012 & 208 & 878 \\
\hline$S-6$ & 虎山 & 6.17 & 3.00 & 733 & 94 & 664 \\
\hline$S-7$ & 接渡 & 6.66 & 3.44 & 523 & 68 & 451 \\
\hline$S-8$ & 镇桥 & 6.91 & 2.26 & 415 & 70 & 586 \\
\hline$S-9$ & 韩家渡 & 6.79 & 2.38 & 439 & 77 & 830 \\
\hline$S-10$ & 石镇街 & 6.68 & 3.20 & 660 & 79 & 624 \\
\hline $\mathrm{S}-11$ & 蔡家湾 & 6.75 & 3.32 & 464 & 75 & 505 \\
\hline$S-12$ & 双港 & 6.86 & 3.36 & 206 & 63 & 293 \\
\hline$S-13$ & 龙口 & 7.05 & 3.79 & 215 & 81 & 226 \\
\hline \multicolumn{2}{|c|}{ 平均值 } & 6.42 & 3.17 & 887.8 & 74.92 & 461.31 \\
\hline 土壤环境质量标准 & (GB15618 - 1995, 三级) & $6.5-7.5$ & - & 400.0 & 500.0 & 500.00 \\
\hline \multicolumn{2}{|c|}{ 鄱阳湖流域底泥背景值 ${ }^{[9]}$} & - & 3.32 & 4.75 & 12.50 & 45.75 \\
\hline
\end{tabular}


从上表可以分析, 与国家土壤环境质量相比,乐安河河流底泥中的 $\mathrm{Cu}$ 含量的平均值超出了三级标准, 但 $\mathrm{Zn}$ 含量的平均值达到了三级标准, $\mathrm{Pb}$ 含量的平均值达到了二级标准. 单个采样点中超标 (以三级标准为 准) 最为严重的为沽口 ( $\mathrm{Cu}, 6.2$ 倍) 和戴村 ( $\mathrm{Zn}, 1.76$ 倍), $\mathrm{Pb}$ 未超标. 同时, 与鄱阳湖流域底泥背景值相比, 所测 3 种重金属元素的平均值分别超过背景值的 5.99 倍 $(\mathrm{Pb})$ 到 185.90 倍 $(\mathrm{Cu})$. 根据超出背景值的倍数 分析,得出乐安河底泥重金属含量顺序为 $\mathrm{Cu}(185.90)>\mathrm{Zn}(10.08)>\mathrm{Pb}(5.99)$.

2.2 .2 乐安河底泥重金属污染评价水体底泥中的重金属含量可作为一个判断标准,用来说明水体中重金 属污染物的循环特征. 目前常用的重金属污染评价方法有重金属污染指标 MPI( Metal pollution index)法、均 方根综合污染指数法、地质累积指数法,脸谱图法等等 ${ }^{[10]}$,但目前对重金属污染评价大多采用地质累积指 数法 ${ }^{[11]}$,本文也运用该方法对乐安河底泥重金属污染进行评价.

地质累积指数法 (index of geo accumulation) 是德国海德堡大学沉积物研究所的科学家 Muller 于 1979 年提出的,在欧洲被广泛采用,在我国曾被部分学者采用过. 其计算式为: $I_{\text {geo }}=\ln \left[C_{n} /\left(k B_{n}\right)\right]$. 其中, $C_{n}$ 为 实测重金属浓度 $(\mathrm{mg} / \mathrm{kg}) ; B_{n}$ 为鄱阳湖流域底泥背景值, 其中 $\mathrm{Cu}$ 为 $4.75 、 \mathrm{~Pb}$ 为 $12.50 、 \mathrm{Zn}$ 为 $45.75 ; k$ 为可能 会引起背景值的变动而取的系数 (一般取值为 1.5 ). $I_{\text {geo }}$ 值为地质累积指数, 根据 $I_{\text {geo }}$ 值 $0-5$ 将污染等级分 为 7 级, 对应污染程度为无污染至极强污染 $(\text { 表 } 3)^{[12]}$.

表 3 地质累积指数与污染分级

Tab. 3 Comparison of pollution level and $I_{\text {geo }}$

\begin{tabular}{cccccccc}
\hline$I_{\text {geo }}$ & $<0$ & $0-1$ & $1-2$ & $2-3$ & $3-4$ & $4-5$ & $>5$ \\
\hline 级别 & 0 & 1 & 2 & 3 & 4 & 5 & 6 \\
污染程度 & 清洁 & 轻度污染 & 偏中度污染 & 中度污染 & 偏重度污染 & 重度污染 & 严重污染 \\
\hline
\end{tabular}

表 4 乐安河底泥重金属污染元素的地质累积指数及其分级

Tab. 4 Igeo and rank of heavy metal pollution in sediments of the Le' an River

\begin{tabular}{|c|c|c|c|c|c|c|c|}
\hline \multicolumn{2}{|c|}{ 项目 } & \multicolumn{2}{|c|}{$\mathrm{Cu}$} & \multicolumn{2}{|c|}{$\mathrm{Pb}$} & \multicolumn{2}{|c|}{$\mathrm{Zn}$} \\
\hline 编号 & 名称 & $I_{\text {geo }}$ & 污染程度 & $I_{\text {geo }}$ & 污染程度 & $I_{\text {geo }}$ & 污染程度 \\
\hline$S-1$ & 海口 & 2.3 & 中度污染 & 1.2 & 偏中度污染 & 1.6 & 偏中度污染 \\
\hline$S-2$ & 沽口 & 8.6 & 严重污染 & 1.2 & 偏中度污染 & 1.7 & 偏中度污染 \\
\hline$S-3$ & 中洲 & 8.3 & 严重污染 & 1.2 & 偏中度污染 & 1.6 & 偏中度污染 \\
\hline$S-4$ & 香屯 & 7.9 & 严重污染 & 1.9 & 偏中度污染 & 1.6 & 偏中度污染 \\
\hline$S-5$ & 戴村 & 7.2 & 严重污染 & 3.5 & 偏重度污染 & 3.7 & 偏重度污染 \\
\hline$S-6$ & 虎山 & 6.7 & 严重污染 & 2.3 & 中度污染 & 3.3 & 偏重度污染 \\
\hline$S-7$ & 接渡 & 6.2 & 严重污染 & 1.8 & 偏中度污染 & 2.7 & 偏中度污染 \\
\hline$S-8$ & 镇桥 & 5.9 & 严重污染 & 1.9 & 偏中度污染 & 3.1 & 偏重度污染 \\
\hline$S-9$ & 韩家渡 & 5.9 & 严重污染 & 2.0 & 偏中度污染 & 3.6 & 偏重度污染 \\
\hline$S-10$ & 石镇街 & 6.5 & 严重污染 & 2.1 & 中度污染 & 3.2 & 偏重度污染 \\
\hline$S-11$ & 蔡家湾 & 6.0 & 严重污染 & 2.0 & 偏中度污染 & 2.9 & 中度污染 \\
\hline$S-12$ & 双港 & 4.8 & 重度污染 & 1.7 & 偏中度污染 & 2.1 & 中度污染 \\
\hline$S-13$ & 龙口 & 4.9 & 重度污染 & 2.1 & 中度污染 & 1.7 & 偏中度污染 \\
\hline \multicolumn{2}{|c|}{ 平均值 } & 6.2 & 严重污染 & 1.9 & 偏中度污染 & 2.5 & 中度污染 \\
\hline
\end{tabular}

依据地质累积指数标准和乐安河底泥重金属含量计算各采样点的地质累积指数和分级 (表 4). 可以 看出, 乐安河不同点的重金属污染程度各不相同, 污染情况中 $\mathrm{Cu}$ 为严重污染, $\mathrm{Pb}$ 为偏中度污染, $\mathrm{Zn}$ 为中度 污染. 总体上看, 鄱阳湖乐安河段目前主要表现为 $\mathrm{Cu}$ 污染, 且污染区主要在德兴铜矿所在区, 即沽口至虎 山. $\mathrm{Pb}$ 和 $\mathrm{Zn}$ 也表现出不同程度的污染. 


\section{3 重金属污染对水生生物的影响}

2.3.1 水生植物富集重金属的特性 本文采得的水生植物样品主要为乐安河底泥上的水生维管束植物, 由 于沿河范围大, 故选取了未污染区和污染严重的具有代表性的区域, 即从海口到戴村. 每处采样点采得样品 若干,样品带回到实验室进行处理分析,具体的测定结果见表 5.

表 5 乐安河不同采样点水生植物中各种重金属元素含量 *

Tab. 5 Concentration of heavy metals of aquatic plants in different sampling sites of the Le' an River

\begin{tabular}{|c|c|c|c|c|c|c|c|c|}
\hline \multirow{2}{*}{ 地点 } & 植物 & & \multirow{2}{*}{ 多度 } & \multirow{2}{*}{$\begin{array}{l}\text { 盖度 } \\
(\%)\end{array}$} & \multirow{2}{*}{$\begin{array}{l}\text { 频度 } \\
(\%)\end{array}$} & \multirow{2}{*}{$\begin{array}{c}\mathrm{Cu} \\
(\mathrm{mg} / \mathrm{kg})\end{array}$} & \multirow{2}{*}{$\begin{array}{c}\mathrm{Pb} \\
(\mathrm{mg} / \mathrm{kg})\end{array}$} & \multirow{2}{*}{$\begin{array}{c}\mathrm{Zn} \\
(\mathrm{mg} / \mathrm{kg}\end{array}$} \\
\hline & 名称 & & & & & & & \\
\hline \multirow[t]{8}{*}{ 海口 } & 苦草 & Vallisneria spiralis $\mathrm{L}$. & $\mathrm{COP}^{3}$ & 90 & 100 & 21.76 & 9.63 & 18.94 \\
\hline & 灯心草 & Juncus effusus L. & $\mathrm{COP}^{1}$ & 50 & 100 & 11.65 & 12.36 & 16.98 \\
\hline & 金鱼藻 & Ceratophyllum demersrm L. & $\mathrm{COP}^{2}$ & 60 & 100 & 12.17 & 4.32 & 18.99 \\
\hline & 马来眼子菜 & Potamogeton malaianus Miq. & $\mathrm{COP}^{2}$ & 80 & 100 & 9.18 & 6.21 & 7.17 \\
\hline & 眼子菜 & P. distinctus A. & $\mathrm{COP}^{2}$ & 80 & 100 & 13.44 & 3.23 & 17.18 \\
\hline & 菹草 & P. crispus L. & $\mathrm{COP}^{1}$ & 40 & 100 & 12.12 & 6.21 & 26.08 \\
\hline & 轮叶黑藻 & Hydrilla verticillata ( L. f. ) Royle & $\mathrm{COP}^{3}$ & 90 & 100 & 21.98 & 11.12 & 22.59 \\
\hline & 茶菱 & Trapella Sinensis Oliver & $\mathrm{SP}$ & 8 & 50 & 7.00 & 1.76 & 27.59 \\
\hline \multirow[t]{6}{*}{ 杜村 } & 金鱼藻 & Ceratophyllum demersrm L. & $\mathrm{COP}^{2}$ & 60 & 100 & 22.32 & 6.32 & 24.47 \\
\hline & 轮叶黑藻 & Hydrilla verticillata ( L. f. ) Royle & $\mathrm{COP}^{2}$ & 80 & 100 & 27.46 & 12.22 & 37.40 \\
\hline & 苦草 & Vallisneria spiralis $\mathrm{L}$. & $\mathrm{COP}^{3}$ & 90 & 100 & 23.63 & 13.69 & 22.40 \\
\hline & 马来眼子菜 & Potamogeton malaianus Miq. & $\mathrm{COP}^{1}$ & 50 & 100 & 22.45 & 10.39 & 40.45 \\
\hline & 眼子菜 & P. distinctus A. & $\mathrm{COP}^{1}$ & 60 & 100 & 34.21 & 9.78 & 20.80 \\
\hline & 小茨藻 & N. minor All. & $\mathrm{SP}$ & 10 & 100 & 29.33 & 6.28 & 19.80 \\
\hline \multirow[t]{2}{*}{ 中洲 } & 慈菇 & Sagittaria sagittifolia $\mathrm{L}$. & un & 5 & 10 & 146.02 & 23.37 & 18.18 \\
\hline & 李氏禾 & Leersia hexandra Swartz. & un & 5 & 10 & 205.36 & 22.41 & 22.75 \\
\hline 中洲下 & 轮叶黑藻 & Hydrilla verticillata ( L. f. ) Royle & $\mathrm{SO}^{1}$ & 8 & 30 & 286.32 & 24.00 & 36.49 \\
\hline \multirow[t]{2}{*}{ 江村坂 } & 轮叶黑藻 & Hydrilla verticillata ( L. f. ) Royle & SP & 10 & 10 & 217.44 & 31.19 & 29.12 \\
\hline & 石龙尾 & L. sessiliflora Baill. & $\mathrm{SP}$ & 8 & 10 & 269.21 & 28.37 & 35.46 \\
\hline \multirow[t]{3}{*}{ 香屯 } & 角果藻 & Zannichellia palustris $\mathrm{L}$. & $\mathrm{COP}^{1}$ & 40 & 50 & 166.31 & 28.65 & 22.15 \\
\hline & 轮叶黑藻 & Hydrilla verticillata ( L. f. ) Royle & $\mathrm{COP}^{1}$ & 70 & 100 & 192.08 & 32.34 & 21.10 \\
\hline & 李氏禾 & Leersia hexandra Swartz. & $\mathrm{SO}^{1}$ & 10 & 30 & 126.33 & 27.68 & 28.59 \\
\hline 戴村 & 李氏禾 & Leersia hexandra Swartz. & $\mathrm{SP}$ & 10 & 50 & 162.93 & 37.35 & 36.20 \\
\hline
\end{tabular}

* $\mathrm{COP}^{3}$ 表示很多, $\mathrm{COP}^{2}$ 表示多, $\mathrm{COP}^{1}$ 表示尚多, $\mathrm{SP}$ 表示少, $\mathrm{SO}^{1}$ 表示稀少, un 表示唯一.

表 5 结果显示,各样点不同植物对 $\mathrm{Cu}, \mathrm{Pb}, \mathrm{Zn}$ 都有不同程度的吸收与富集,而且植物对重金属元素的富 集与环境背景值的含量具有一定的相关性. 由于乐安河环境中 $\mathrm{Cu}$ 和 $\mathrm{Zn}$ 的含量较高, 各种植物对铜和锌的 富集也表现出较高的含量; 同时,各种植物的对 $\mathrm{Pb}$ 也表现出一定的吸收与富集,但富集含量相对较低些; 而 且, 从实际的采样点情况和上表还可看出, 沽口和中洲至香屯, 甚至戴村一带污染区的河滩大多数植物中的 重金属含量要明显高于海口和杜村, 这表明植物吸收富集重金属元素与土壤背景值呈正相关, 土壤背景含 量越高,植物吸收得越多, 表现出重金属从土壤 (底泥) 向植物迁移的主要特征 ${ }^{[13]}$.

植物对重金属元素的富集与植物种类、植物生态习性以及环境等密切相关 ${ }^{[14]}$, 因此不同采样点相同植 物或者同一采样点不同植物对重金属元素的富集都存在一定的差异. 为了反映不同植物在不同环境中对不 同重金属元素的富集能力,本文采用富集系数 $(K)$ 进行定量评价,富集系数的计算公式为: $K=C_{o i} / C_{e i}$. 式 中, $C_{o i}$ 为受检植物体内某种重金属元素的残留量 $(\mathrm{mg} / \mathrm{kg}) ; C_{e i}$ 为受检植物所在环境中重金属的实测浓度 $(\mathrm{mg} / \mathrm{kg}) . K$ 值大小表明受检植物对环境中重金属的富集能力, 根据各种植物中的残留量及底泥环境中的 
实测值,计算不同样点、不同植物对重金属元素的富集系数,并对乐安河流域各样点采得的不同植物中的各 种重金属元素的富集系数进行分析比较(图 2,图 3).

图 2 中取未受污染的海口和污染严重的香屯处的水生植物为研究对象, 从图中可以明显看出乐安河段 重金属元素在不同植物中的迁移转化具有不同的特性,同一样点不同植物对不同重金属元素的富集具有一 定的选择性和差异性, 在未受到污染的海口处,一般植物对 $\mathrm{Cu}$ 的富集能力相对较强些, 其次是 $\mathrm{Pb}$ 和 $\mathrm{Zn}$, 而 污染区的植物对 $\mathrm{Pb}$ 富集能力相对更强些, 其次是 $\mathrm{Zn}$ 和 $\mathrm{Cu}$. 图 3 中以轮叶黑藻为研究对象, 不同采样点轮 叶黑藻的富集也存在一定的差异性,表现出植物的富集与环境背景值之间存在一定的正相关性.

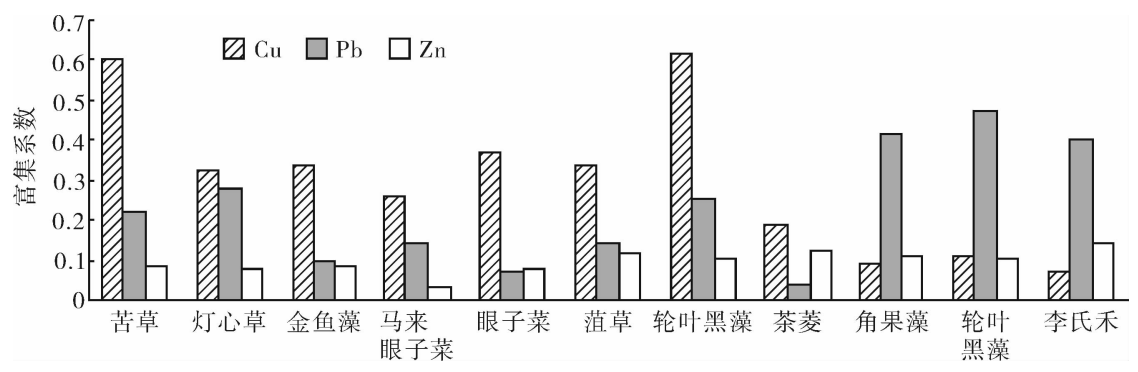

图 2 同一采样点不同植物对重金属元素富集系数的比较

Fig. 2 Coefficient of different plants in the sampling sites

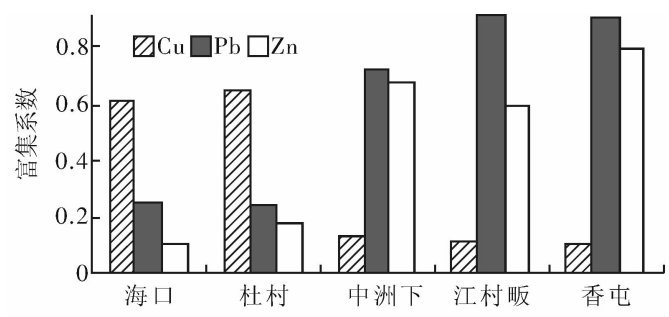

图 3 不同采样点同种植物对重金属元素富集系数的比较

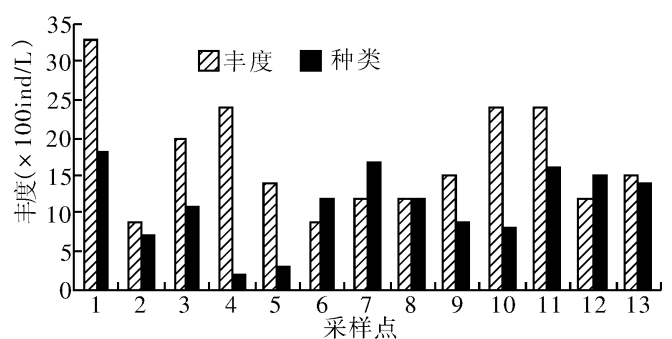

图 4 乐安河浮游动物种类分布及数量变化

Fig. 3 Coefficient of the plant in different sampling sites Fig. 4 Distribution of zooplankton along the Le' an River

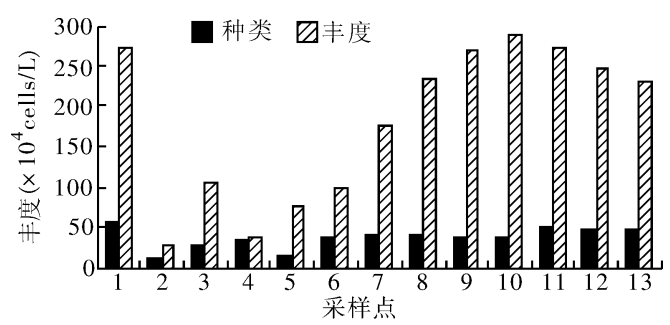

图 5 乐安河浮游植物分布及数量变化

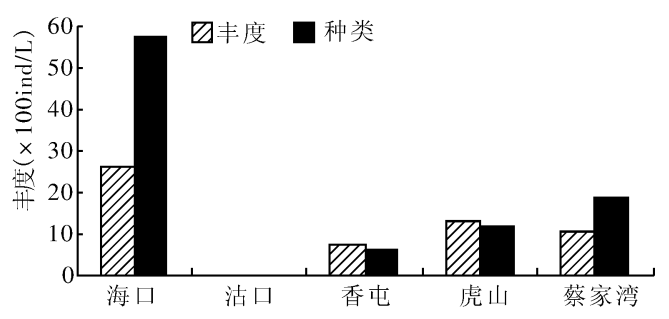

图 6 乐安河底栖动物种类分布及数量变化

Fig. 5 Distribution of phytoplankton along the Le' an River Fig. 6 Distribution of benthos species along the Le' an River

2.3.2 重金属对水生浮游动植物和底栖动物的影响 乐安河重金属的污染涉及整个流域, 因此本文还相应 采集了水生浮游动植物和底栖动物样品, 计算相应的丰度值, 以了解污染的分布情况 (图 4 - 图 6).

浮游动物的种类和数量与水质密切相关 ${ }^{[15,16]}$, 沽口仅见 7 种原生动物, 与海口相比有很大的锐减, 中 洲也只有 11 种原生动物, 至香屯和戴村达到最低, 至虎山开始恢复, 到蔡家湾, 种类已完全恢复但甲壳类种 类仍少于上游海口点. 浮游植物的种类从海口到龙口变化不大, 在污染区沽口至戴村较低, 但浮游植物数量 变化很大, 相对未污染区海口和韩家渡以下的下游水域, 污染区的浮游植物数量很低. 浮游植物的分布和数 
量变化基本反映出了乐安河水质的变化, 即从海口至沽口, 水质急剧变差, 至戴村河和虎山有所回复, 到韩 家渡基本恢复正常. 乐安河中,沽口以上的河段尚能采集到底栖动物 (共 26 种)包括部分对含氧较敏感的 螺蚌类以及摇蚊类的某些种类如 (短沟蜷、隐摇蚊和摇蚊幼虫) 等. 沽口由于受到污染较为严重, 几乎采不 到底栖动物, 直到香屯由于河流的自净稀释作用, 才能找到少量的螺类,下游从虎山开始底栖动物逐渐恢 复,但种类和数量都不及上游的海口, 可见底栖动物对重金属污染极其敏感 ${ }^{[17,18]}$.

从乐安河流域浮游动物、浮游植物和底栖动物的分布及数量变化来看, 三者的变化基本保持一致,说明 乐安河流域的重金属污染已经呈现复合污染的趋势,这主要是与上游德兴铜矿的长期开采和水域中三者之 间的食物链关系有关.

\section{3 结论}

乐安河水体、底泥和水生生物所受的污染总体一致, 目前主要表现为 $\mathrm{Cu}$ 污染, $\mathrm{Pb}$ 和 $\mathrm{Zn}$ 也相应出现不 同程度的污染, 整个流域有出现复合污染的趋势. 污染程度也不一样, 底泥污染最为严重, 其次是水生生物, 水体污染相对较轻,这与重金属的迁移转化特性的理论相符.

\section{4 参考文献}

[1] 万 兴,万金保. 江西乐安河水质现状及综合整治措施. 中国人口・资源与环境, 2006,16(1):285 -288 .

[3] 黄学平,万金保. 乐安河水环境现状及其治理措施. 长江流域资源与环境, 2005,14(6): 770 - 774 .

[4] 国家环境保护总局编. 水和废水监测分析方法 (第四版). 北京: 中国环境科学出版社,2002.

[5] 中国环境监测总站编著.土壤元素的近代分析方法. 北京: 中国环境科学出版社,1992:64-73.

[6] 中国标准出版社第二编辑室编. 水质分析方法国家标准汇编. 北京: 中国标准出版社, 1996 .

[7] 万金保,黄学平. 采用等标污染负荷法分析大坞河水污染特征. 南昌工程学院学报,2005,24(1):35 -38 .

[8]王小庆. 水环境条件对重金属迁移转化的影响. 洛阳工业高等专科学校学报,2006,16(1):3-4.

[9] 鄱阳湖研究编委会. 鄱阳湖研究.上海:上海科学技术出版社, 1988.

[10] 张 金金,周涛发,杨西飞等. 河流沉积物重金属污染评价方法比较研究. 合肥工业大学学报 (自然科学 版), 2005,28(11): $1419-1423$.

[11] 何孟常,王子健. 利用综合评价方法和等级模型评价乐安江水体重金属污染. 生态学报, 2002,22(1): $80-86$.

[12] 尚英男,倪师军,张成江等. 应用地质累积指数评价成都市河流表层沉积物重金属污染.广东微量元素 科学, $2005,12(10): 12-16$.

[13] 简敏菲,弓晓峰,游 海等. 鄱阳湖水土环境及其水生维管束植物重金属污染. 长江流域资源与环境, $2004,13(6)$ ):589 - 593.

[14] 简敏菲,弓晓峰,游 海. 鄱阳湖流域重金属污染对湖区湿地生态功能的影响及防治对策. 江西科学, 2003,21 ( 3 ) : $230-234$.

[15] 王新华,纪炳纯, 罗 阳等. 引㴒工程上游浮游动物及其水质评价. 城市环境与城市生态, 2003,16(6): $243-245$.

[16] 刘春明,易国栋.二龙湖水库浮游动物调查与水质评价. 东北师大学报 (自然科学版),2000,32(4):63 -66 .

[17] 朱 江,任淑智. 德兴铜矿废水对乐安江底栖动物群落的影响. 应用与环境生物学报, 1996,2(2):162 -168 .

[18] 毕春娟,陈振楼, 许世远等. 长江口潮滩大型底栖动物对重金属的累积特征. 应用生态学报, 2006,17 (2) :309-314. 